the persistence of a renal disturbance far greater than that usually seen in cardiac failure.

The simplest explanation of our findings is that they are a nonspecific stress response, but we have found normal results in patients equally ill from other causes. Espiner (1966), in a study of patients with " medical stress," found raised urinary cortisol excretion accompanied by an increase in the plasma levels, particularly early in the stress period. One of his patients who also was in cardiac failure had plasma cortisol levels similar to those of our patients. We have observed our patients after the first day of admission and seen abnormalities in plasma cortisol levels throughout an episode of cardiac failure. One patient (Case 1) did not show normal suppression with dexainethasone. These results suggest that there might be an alternative mechanism, possibly outside the pituitary-adrenal axis. This might be related to the known abolition of the circadian rhythm of urinary water and electrolyte excretion in congestive cardiac failure (Brod and Fejfar, 1950 ; Baldwin, Sirota, and Villarreal, 1950; Goldman and Luchsinger, 1956) the mechanism of which is not yet fully elucidated.

Some patients with cardiac failure have secondary aldosteronism. Haemodynamic changes induce a rise in reninangiotension production, which is largely, if not entirely, responsible for increased aldosterone secretion (Conn, Cohen, and Rovner, 1964). The method used in this study estimates both cortisol and corticosterone. Bledsoe, Island, and Liddle (1966) reported that sodium depletion caused an increased production of aldosterone precursors in subjects maintained on dexamethasone. Secretion of corticosterone, which occurs in the aldosterone metabolic pathway, was increased, while cortisol secretion was unaffected. Thus the possibility that we are observing an increase in corticosterone levels rather than cortisol must be considered.

In the only previous study of cortisol levels in heart failure that we were able to find the authors reported high plasma levels at an unstated time in the evening, with normal morning levels (Pekkarinen, Iisalo, Kasanen, Laihinen, and Thomasson, 1960). They did not report such a complete return to normal as we have seen, nor did they report failure to suppress cortisol secretion with dexamethasone.

Further investigations are being carried out in an attempt to elucidate our findings and if possible to correlate them with the disturbance in the electrolyte and water excretion. We report them at this preliminary stage because we feel that the diagnosis of Cushing's syndrome, based on plasma cortisol levels, in patient's with concomitant congestive cardiac failure should be made with caution.

\section{Summary}

Abolition of the circadian rhythm in plasma cortisol levels, with elevation of the midnight values, is reported in five patients with congestive cardiac failure. The disturbance in rhythm persisted throughout an episode of failure and appears to be $\overline{0}$ unrelated to other nonspecific stress mechanisms. The possible $\underline{0}$ mechanisms causing these disturbances are discussed. These findings are of importance in the differential diagnosis of $\mathbb{D}$ Cushing's syndrome, based on plasma cortisol levels where there is concomitant congestive cardiac failure.

\section{RBFERENCES}

Baldwin, D. S., Sirota, J. H., and Villarreal, H. (1950). Proc. Soc. exp. Biol. (N.Y.), 74, 578 .

Bledsoe, T., Island, D. P., and Liddle, G. W. (1966). F. clin. Invest., $45,524$.

Brod, J., and Feifar, Z. (1950). Quart. F. Med., 19, 187.

Brown, H., Willardson, D. G., Samuels, L. T., and Tyler, F. H. (1954). 7. clin. Invest., 33, 1524.

Conn, J. W., Cohen, E. L., and Rovner, D. R. (1964). f. Amer. med. Ass., $190,213$. Doe, R. P., Vennes, J. A., and Flink, E. B. (1960). 7. clin. Endocr., 20,

Ekman, H., Håkansson, B., McCarthy, J. D., Lehmann, J., and Sjögren, B. (1961). Ibid., 21, 684

Englert, E., Brown, H., Wallach, S., and Simons, E. L. (1957). Ibid., I 17, 1395. Willardson, D. G., Wallach, S., and Simons, E. L. (1958). Ibid., 18, 36

Nelson, R. M., Brown, H., Nielsen, T. W., and Chou, S. N. (1960). Surgery, 47, 982 .

Espiner, E. A (i9k6). F. Rndocr., 35, 29.

Goldman, R., and Luchsinger, E. B. (1956). 7. clin. Endocr., 16, 28.

Jenkins, J. S. (1961). In The Adrenal Cortex, edited by G. K. McGowan and $M$. Sandler. London.

Klein, R., Papadatos, C., Fortunato, J., Byers, C., and Puntereri, A. (1955). 7. clin. Endocr., 15, 943.

Longson, D., and Christy, N. P. (1964). In Biochemical Disorders in Human Disease, edited by R. H. S. Thompson and E. J. King, 2nd Human Disease, London.

Mattingly, D. (1962). 7. clin. Path., 15, 374.

Mills, J. N. (1966). Phystol. Rev., 46, 128.

Pekkarinen, A., Iisalo. E., Kasanen, A., Laihinen, A., and Thomasson, B. (1960). Amer. 3. Cardiol., 5, 604

Peterson, R. E. (1960). \%. clin. Invest., 39, 320.

Ross, E J., Marshall-Jones, P., and Friedman, M. (1966). Quart. 7. Med. 35, 149.

Sandberg, A. A., Eik-Nes, K., Migeon, C. J., and Samuels, L. T. (1956) 9. clin. Endocr., 16, 1001 .

Tucci, J. R., Albacete, R. A., and Martin, M. M. (1966). Gastroenterology, 50, 637.

\title{
Circadian Rhythm of Plasma 11-Hydroxycorticosteroids in Depressive Illness, Congestive Heart Failure, and Cushing's Syndrome
}

\author{
M. S. KNAPP,* M.B., M.R.C.P. ; P. M. KEANE, $†$ M.B., M.C.PATH. ; J. G. WRIGHT, $¥$ M.B., CH.B., D.P.M.
}

Brit. med. F., 1967, 2, 27-30

A well-marked circadian rhythm-that is, a rhythm with a periodicity of 24 hours-in the adrenal output of cortisol was first suspected from the pattern of urinary 17-hydroxycorticosteroid excretion (Pincus et al., 1948). This was confirmed by Migeon et al. (1956), who measured plasma levels of 17-hydroxycorticosteroids. Doe et al. (1960) reported the absence of this rhythm in Cushing's syndrome. A study of plasma cortisol, as 17-hydroxycorticosteroid or as free 11hydroxycorticosteroid content, at two or more times in the day has now become a standard investigation in cases of suspected

- Lecturer in Medicine, University of Bristol

$t$ Sentor Registrar in Chemical Pathology. Bristol Royal Infirmary.

¥ Lecturer in Mental Health, University of Bristol.
Cushing's syndrome (Cope, 1965, 1966). A knowledge of the circadian rhythm of 11-hydroxycorticosteroid in other diseases is therefore of increasing importance.

Perkoff et al. (1953) studied 80 patients in an American hospital. They found that the plasma 17-hydroxycorticosteroid rhythm was similar to that of healthy people not in hospital, except in patients with disturbed consciousness or with fever. The only difference was in the level at 04.00 hours. This was usually higher in subjects in hospital and closer to the level at 08.00 hours than to that at 24.00 hours. A possible explanation is the early hour of awakening in American hospitals. These authors did not include patients with psychiatric illness, cardiac failure, or Cushing's syndrome. Pekkarinen et al. (1960) pub- 
Group 2 (see Fig. 2 and Table III).-As a group their plasma 11-hydroxycorticosteroids were not significantly different from those of the control subjects except at 04.00 hours. At this time they were significantly higher than in the control group $(\mathrm{P}<0.001)$, the values having reached the levels normally seen at 08.00 hours.

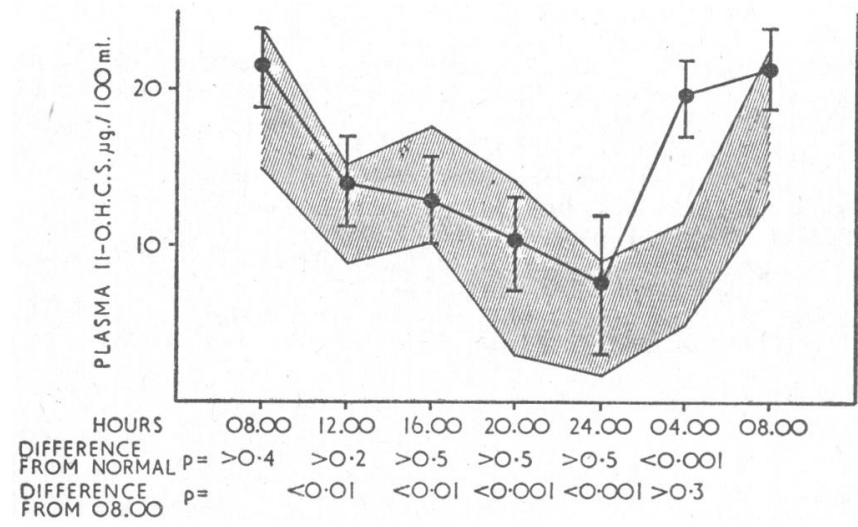

FIG. 2.-Mean concentration ( \pm 1 S.D.) of 11-hydroxycorticosteroid ( $\mu \mathrm{g} . / 100 \mathrm{ml}$.) from patients with depressive illness (group 2). The shaded area represents +1 S.D. from the mean values of control subiects.

Group 3 (see Fig. 3 and Table III).-When considered as a group these patients with congestive heart failure showed no thythm in their plasma 11-hydroxycorticosteroids. The mean levels were in the normal range until 16.00 hours, after which the mean level and most individual levels were above normal. Two patients (Cases 12 and 15), both with low normal daytime values, had a normal rhythm. The only other patient with chronic rheumatic heart disease (Case 16) had a normal rhythm except for the high value at 04.00 hours.

Group 4 (see Fig. 4 and Table III).-All the patients with Cushing's syndrome showed little variation in plasma 11hydroxycorticosteroids.

\section{Discussion}

Mills (1966) had pointed out that unless serial samples are taken throughout 24 hours the troughs and peaks of a circadian rhythm may be missed. We have attempted to avoid this source of error by taking seven specimens over 24 hours. In previous work on patients with congestive heart failure samples were taken at 08.00 and 20.00 hours only.

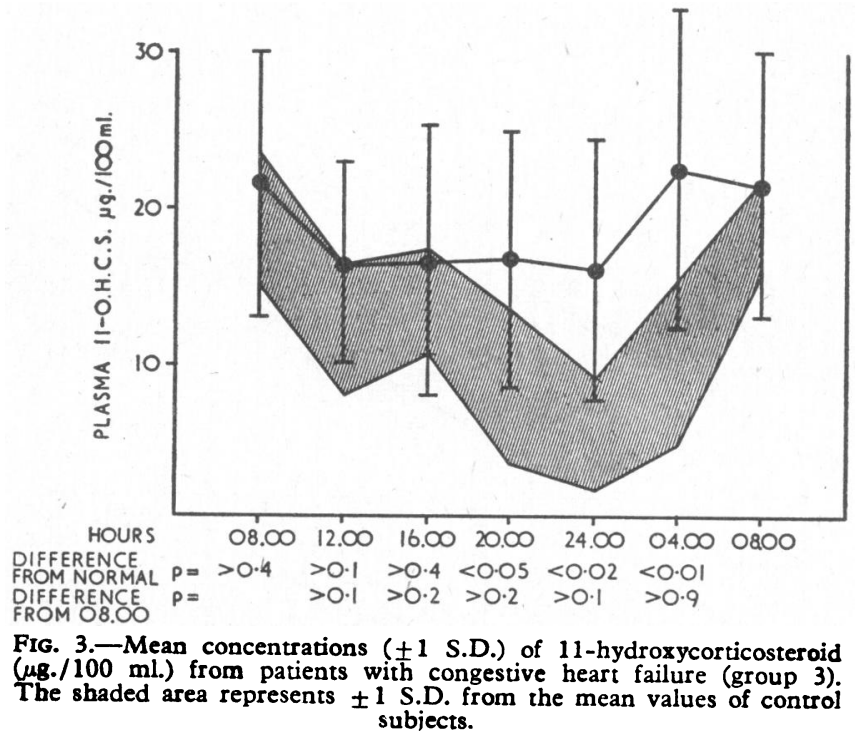

The abnormal rhythm which we have shown in patients with depressive illness affects only the period after midnight. It may perhaps be related to the history and observation that all these patients had the typical early waking that occurs in this condition. The normal rhythm of plasma 11-hydroxycorticosteroids has been lost in most of the patients with heart failure. The three patients with heart failure who had a nearly normal $\mathbb{D}$ rhythm had chronic rheumatic heart disease. They had all been in heart failure before. There did not seem to be any other

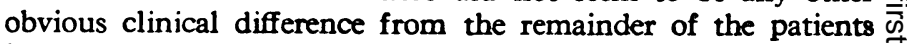
in this group.

Previous workers have shown absent rhythm in Cushing's syndrome due to adenoma, carcinoma, or hyperplasia. This $\frac{\bar{m}}{T}$ may result in normal morning levels but high levels later in $\mathbb{D}$ the day. We have confirmed this finding. We have studied

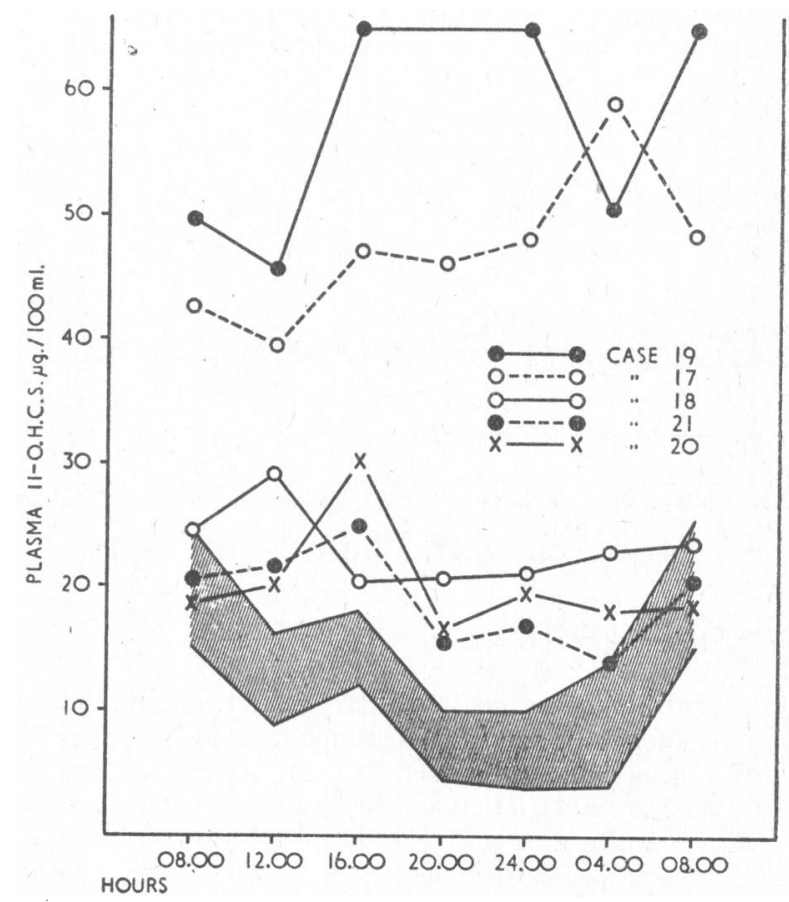

Fig. 4.-Plasma 11-hydroxycorticosteroid ( $\mu \mathrm{g} . / 100 \mathrm{ml}$ ) from five cases of Curhing's syndrome. The shaded area represents \pm 1 S.D. from the mean values of control subjects.

a patient, not included in this paper, who had Cushing's syndrome with a normal rhythm; similar cases have been described in the literature (Ekman et al., 1961). In most patients, however, the absent rhythm is constant enough to allow the use of a single evening estimation of plasma cortisol as a valuable diagnostic test (Doe et al., 1960; Ekman et al., 1961; Mattingly, 1963). The absence of normal variations in plasma 11-hydroxycorticosteroids in heart failure could also cause confusion when heart failure and Cushing's syndrome may coexist.

It is interesting to consider the influence of the changes described on the circadian rhythm of renal function. Patients in congestive heart failure, with depressive illness or with Cushing's syndrome, sometimes have a higher than normal output of urine and electrolytes at night. The primary cause of this may be the disturbance in the circadian rhythm of adrenal function.

\section{Summary}

Plasma 11-hydroxycorticosteroids have been "measured in plasma samples taken at four-hourly intervals over 24 hours from patients with depressive illness, congestive heart failure, and Cushing's syndrome. In those with depression a normal circadian rhythm was found, except at 04.00 hours. In con- 
gestive heart failure and Cushing's syndrome it is unusual to have any obvious rhythm.

ADDENDUM.-Since submitting this paper for publication two reports have appeared of plasma cortisol values in depressive illness. Doig et al. (1966) have reported levels at 24.00, 03.00 , and 06.00 hours and found a significant difference from controls only at 06.00 hours. Bridges and Jones (1966) have shown in their patients that between 09.30 and 21.30 hours a significant fall in plasma cortisol occurs, as in the depressives we have studied, though the mean values were higher than in our group of patients.

We are grateful to Professor C. B. Perry, Prnfessor D. Russell Davis, Dr. J. E. Cates, and Dr. G. K. McGowan for their help, advice, and encouragement. We would also like to thank Mrs. A. Morris for help in preparing the results for statistical analysis in the computer unit of the University of Bristol.

\section{REFERENCES}

Bridges, P. K., and Jones, M. T. (1966). Brit. F. Psychiat., 112, 1257. Cope, C. L. (1965). Proc. roy. Soc. Med., 58, 55. - (1966). Brit. med. F., 2, 847.

Doe, R. P., Vennes, J. A., and Flink, E. B. (1960). F. clin. Endocr., 20. 253.

Doig, R. J., Mummery, R. V., Wills, M. R., and Elkes, A. (1966). Brit. f. Psychiat., 112, 1263.

Ekman, H., Häkansson, B., McCarthy, J. D., Lehmann, J., and Sjögren. B. (1961). 7. clin. Endocr., 21, 684.

Iisalo, E., and Pekkarinen, A. (1965). Ann. Med. intern. Fenn., 54, 121.

Lobban, M., Tredre, B., Elithorn, A., and Bridges, P. (1963). Nature (Lond.), 199, 667.

Mattingly, D. (1962). F. clin. Path., 15, 374.

- (1963). Proc. roy. Soc. Med., 56, 717.

Mizeon, C. J., et al. (1956). F. clin. Endocr., 16, 622.

Mills, J. N. (1966). Physiol. Rev., 46, 128.

Pekkarinen, A., Ijealo, E., Kasanen, A., Laihinen, A., and Thomasson. B. (1960). Amer. F." Cardiol., 5, 604.

Perkoff, G. T., et al. (1959). Y. clin. Endocr., 19, 432.

Pincus, G., Romanoff, L. P., and Carlo, J. (1948). Ibid., 8, 221.

\section{Preliminary Communications}

\section{Relation between Maximal Acid Output of Stomach and Lean Body Mass}

Brit. med. F., 1967, 2, 30-31

The diagnostic value of the augmented histamine test (Kay, 1953) or of any other standard measure of gastric secretory function is seriously impaired by the marked overlap which exists between results obtained in a variety of gastric disorders, including peptic ulcer and gastric cancer, and those found in healthy subjects (Bruce et al., 1959). Attempts to clarify the position by establishing significant associations between maximal acid output and body build by measurements of height, weight, and surface area in both normal adults and ulcer patients have failed (Baron, 1964). However, Ghai et al. (1965) were able to demonstrate a significant correlation $(r=0.81)$ between body weight and maximal acid output in 16 healthy Indian children. Scrutiny of the data of these authors indicated that the mean weight of the children was $25.3 \mathrm{~kg}$. ; this was at least $10 \mathrm{~kg}$. less than the corresponding expected weight of similar children in the United States as calculated from the tables of Nelson (1959). It seemed to us that a possible explanation of this discrepancy in weight might be that, for dietary reasons, the Indian children had less adipose tissue, and therefore their total body weight would tend to approach more closely the lean body mass or fat-free body weight. This paper presents preliminary observations which show that there is a significant correlation between maximal acid output and lean body mass in both normal adults and duodenal ulcer subjects.

\section{Methods and Materials}

Normal Subjects ( 3 male, 5 female).-These were healthy volunteers whose ages ranged from 20 to 51 , with a mean of 28.4 years. They had no dyspeptic symptoms or a family history of ulcer.

Ulcer Subjects (20 male, 3 female).-Their ages ranged from 16 to 65 , with a mean of 41.5 years. Each had a radiologically proved duodenal ulcer.
Maximal acid output was measured by the augmented histamine test meal of Kay (1953).

Lean body mass was calculated from height and weight by the formula of Hume (1966), which is based on the measurement of total body water.

\section{Discussion}

Analysis of the normal group (see Chart) shows that there is a significant correlation between the maximal acid output and lean body mass $(P<0.01 ; r=0.90)$. Since the maximal acid output is believed to be directly related to the parietal cell mass (Marks, 1956 ; Card and Marks, 1960), it follows that the parietal cell mass correlates with the lean body mass. The low

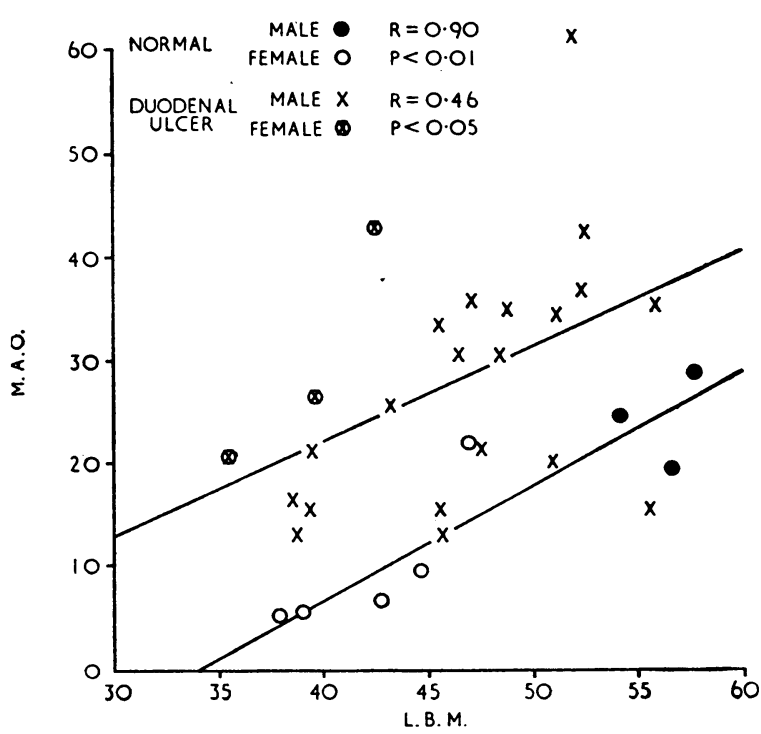

L.B.M. = Lean body mass in kilograms. M.A.O. = Maximal acid output in mEq $\mathrm{HCl}$. Normal group : Regression line of $y$ (M.A.O.) on $x$ (L.B.M.) is given by $y=1.0932 x-36.75$. The standard deviation of deviations from the regression line is 19.0. Duodenal ulcer group: Regression line of $y$ (M.A.O.) is 19.0. Duodenal ulcer group : Regression line of $y$ (M.A.O.)
on $x$ (L.B.M.) is given by $y=0.929 x-15.17$. The standard $x$ (L.B.M.) is given by $y=0.929 x-15.17$. The standard
deviation of deviations from the regression line is 112.9 . 